\section{Hashimoto's Thyroiditis and Thyroid Cancer}

\section{José Manuel Gómez Sáez*}

Department of Endocrinology, University of Barcelona, Hospital Universitario de Bellvitge, Spain

\section{Abstract}

The association between Hashimoto's thyroiditis and thyroid follicular epithelium cancer, such as papillary carcinoma, remains unclear. The evidence, from several countries, is that thyroid cancer frequency is increasing and this increase is due to a higher frequency of papillary cancer and some factors that had been considered in the increase are nutritional dietary iodine intake and the higher prevalence of chronic thyroiditis. There are difficulties to clarify this relationship because the criteria for defining chronic Hashimoto's thyroiditis are heterogeneous in the different series studied. In patients with thyroid nodules, elevated serum concentration of anti-thyroglobulin antibodies and thyroid stimulating hormone higher than $1 \mu \mathrm{lu} / \mathrm{ml}$ seems to be independent predictors factors for thyroid cancer.

Different studies have shown that concurrent chronic lymphocytic thyroiditis and papillary carcinoma are associated to better tumor prognosis.

It should be elucidated whether Hashimoto's thyroiditis predisposes to development of papillary thyroid carcinoma, or is an incidental finding, or thyroiditis is part of a host response to the tumor. In the absence of more evidence, patients with Hashimoto's thyroiditis, and mainly those with the nodular variant, must be regularly monitored, and the possibility of development of papillary carcinoma must be consider, either at diagnosis or during follow-up because some the patients can develop a thyroid tumor.

Keywords: Chronic autoimmune thyroiditis; Hashimoto's thyroiditis; Papillary thyroid carcinoma; Thyroid follicular epithelium cancer
\end{abstract}

\section{Introduction}

Hashimoto's thyroiditis is part of the spectrum of autoimmune thyroid diseases and is associated with various degrees of thyroid hypofunction and presents circulating antibodies to thyroid antigens; the incidence of Hashimoto's thyroiditis seems to be increasing in recent years. It is a disease of young and middle age and mostly occurs

*Corresponding author: José Manuel Gómez Sáez, Department of Endocrinology, University of Barcelona, Hospital Universitario de Bellvitge, Spain, Tel: +34 686480075; E-mail: josemanuelgomezsaez@gmail.com

Citation: Sáez JMG (2016) Hashimoto's Thyroiditis and Thyroid Cancer. J Hum Endocrinol 1: 003.

Received: February 29, 2016; Accepted: April 15, 2016; Published: April 30, 2016

Copyright: (C) 2016 Sáez JMG, This is an open-access article distributed under the terms of the Creative Commons Attribution License, which permits unrestricted use, distribution, and reproduction in any medium, provided the original author and source are credited. in females. Diffuse goiter and thyroid hypofunction were the common findings but can present an active phase of the disease that is transient with clinical manifestation of thyrotoxicosis. Nodules also represent an early stage of the disease. Evolution and destructive phases manifest with subclinical and overt hypothyroidism. It is the most common autoimmune thyroid disease and the most frequent cause of hypothyroidism. The association between simultaneous occurrence Hashimoto's thyroiditis or chronic autoimmune thyroiditis and thyroid follicular epithelium cancer, such as papillary carcinoma, remains not clear and the effect of Hashimoto's thyroiditis on the prognosis of papillary carcinoma has been debated. This relationship has been observed for a long time and continues to be controversial and their coexistence is a real clinical situation whose significance is still unknown [1-4]. Female predominance was observed in patients with chronic autoimmune thyroiditis and thyroid cancer and share some risk factors as greater incidence in areas with adequate supply of iodine or high iodine intake as Korea and some Chinese regions where the prevalence of chronic lymphocytic thyroiditis increased between 1999 and 2008, whereas the prevalence of other thyroid disorders did not change [5,6]; also is more frequent in patients after radiotherapy of the neck and in patients with molecular genetics linkage. There is consistent growing evidence, from several countries, in the last years, that thyroid cancer frequency is increasing and this increase in incidence is due to a higher frequency of papillary cancer $[7,8]$. Possible factors had been considered in the increase, including nutritional, dietary iodine intake and the higher prevalence of chronic thyroiditis and this coexistence has been shown also in children [9] The frequency of this association in surgical series reported an increasing prevalence of $21-30 \%$ in studies performed on thyroidectomy specimens but the prevalence of papillary carcinoma in patients assessed by cytology is $1.2 \%$ [10-15]. A review study has revealed significant differences in the prevalence and the risk ratio of thyroid cancer in Hashimoto's thyroiditis specimens obtained via fine-needle aspiration cytology or thyroidectomy [16]. Thus, both diseases frequently occur simultaneously after surgery but it is not yet clear whether Hashimoto's thyroiditis can be regarded as a risk factor for thyroid malignancy.

There are difficulties to clarify the relationship because the criteria for defining chronic autoimmune thyroiditis that are heterogeneous in the different series studied, because some may be surgical series with pathological samples but other are cytological studies without no subsequent surgery. It is also important the difference between Hashimoto's thyroiditis and lymphocyte infiltration that may be a confounding factor. In this regard, it should be noted that it is important to distinguish between diffuse and focal lymphocytic infiltration around the tumor. The histological finding of Hashimoto's thyroiditis is defined as diffuse lymphocytic infiltration and no peritumoral lymphocytic infiltration; such peritumoral infiltration can represent that the immune system, through lymphocytes, could locate the tumor, and thus prevent recurrence and extension. Thus, the lymphocytic infiltrate may be an immunological response with a cancer retarding effect, contributing to a favorable outcome of papillary cancer compared to other thyroid cancers without lymphocytic infiltration. The consequence is that these patients are also less likely to develop recurrence and have a higher survival rate [17]. An alternative explanation to lymphocyte infiltration is that the tumor itself acts locally, triggering a reaction against the host, which 
would not be generalized. An additional possibility is that lymphatic blockade by tumor thrombi interferes with normal lymphatic return, which would explain the presence of lymphocyte infiltration not only in the classical papillary thyroid carcinoma but also in the diffuse sclerosing or tall cell variants with nodal invasion or in the exceptional cases of follicular carcinoma [5]. It has been observed this infiltration in the warthin variant, that is a subtype of oncocytic papillary carcinoma, and this association has a good prognosis [18]

The prevalence of cancer in patients with Hashimoto's thyroiditis do not appear to be greater in thyroid nodules as compared to those with nodules but without this disease $[19,20]$. On the other hand, thyroid carcinoma is not associated with serum concentrations of thyroid peroxidase antibodies, but in patients with thyroid nodules, elevated serum concentration of anti-thyroglobulin antibodies and thyroid stimulating hormone higher than $1 \mu \mathrm{Iu} / \mathrm{ml}$ are independent predictors for thyroid cancer, thus this association is antibody specific [21-23]. In a recent study, high thyroid antiperoxidase antibodies titers appear to protect against papillary thyroid cancer in patients with chronic thyroiditis [24]. On the contrary, other study, confirms that patients with positive thyroid antibodies have a greater risk of malignancy in those with benign fine needle aspiration cytology and the authors recommend thyroid antibody assessment in addition to cytology for the assessment of thyroid nodules [25].

Papillary carcinoma has been found to be more common in nodules in the setting of lymphocytic thyroiditis and with higher thyroid stimulating hormone levels and the prevalence decrease in subjects treated with L-thyroxin. Papillary thyroid carcinoma would increase by $11 \%$ per each $\mathrm{mIu} / \mathrm{L}$ increase in thyroid stimulating hormone. On the other hand, risk of papillary carcinoma is lower in patients with autonomous toxic nodules, in whom thyroid stimulating hormone levels are lower [13,25-27]. The concomitant occurrence of both diseases would be particularly evident in iodine rich areas, because iodination increases thyroid autoimmunity and increases thyroid stimulating hormone $[5,6]$.

Different studies have shown that concurrent chronic lymphocytic thyroiditis and papillary carcinoma are associated to better tumor prognosis. It has been reported that when is less associated with extrathyroidal extension, advanced tumor stage and lymph node metastasis. Patients with chronic thyroiditis and papillary thyroid carcinoma who underwent central compartment neck dissection have lower proportion of metastatic lymph nodes than those without thyroiditis. Given the relatively low yield of malignant cervical lymphadenopathy, a more careful approach to central compartment neck dissection might be considered, particularly for the youngest and oldest patients with papillary carcinoma and thyroiditis [28-37]. On the contrary, children and adolescents with chronic thyroiditis present more frequently familial papillary thyroid carcinoma as well as thyroid cancer with invasive characteristics [38]. Nevertheless, the influences of chronic thyroiditis on the prognosis of the thyroid carcinoma still need to be investigated with a larger sample size.

From the immune view point, cytotoxic CD3-CD16 and CD56dim cells account for $95 \%$ of the NK population. Proliferation of T and B lymphocytes and thyroid tissue destruction result from a decrease in CD16-NK cells. They have been shown to be increased when both conditions, cancer and chronic thyroiditis, coexist and to be decreased in the presence of cancer alone, in which case they would not be able to suppress tumor progression, with the consequence of more advanced tumor stages [39].
Autoimmune chronic thyroiditis affects the cytokine profile of patients with papillary thyroid carcinoma by stimulating secretion of Th1/Th2/Th9 types of cytokines. Th1/Th2 cytokine ratios in papillary tumor patients with associated autoimmune chronic thyroiditis indicate a marked shift toward Th2 immunity [40]. Activation of the thyroid stimulating hormone receptor may also be significant in stimulation of the Akt pathway, which is important for tumor progression and metastasis; it is not clear, however, to what extent it may influence triggering of a more aggressive disease. The link was supported by the immunohistochemical evidence of increased phosphorylated Akt, Akt1, and Akt2 expression in regions of chronic thyroiditis and thyroid cancer compared with regions of normal surrounding thyroid tissue [15].

Osteopontin, a secreted glycoprotein, plays a role in cell survival, immunity, and tumor progression; its expression is being associated with a poor prognosis and metastasis in several cancers and its over expression correlates with aggressive features in papillary thyroid carcinoma. In papillary thyroid cancer associated to chronic thyroiditis, plasma osteopontin, tissue osteopontin mRNA, and tissue osteopontin protein levels were significantly lower in patients than papillary thyroid cancer alone, suggesting that chronic thyroiditis attenuates papillary thyroid cancer aggressiveness [41].

Elevated thyroid stimulating hormone concentrations may also predispose to the BRAF mutation that is related more advanced tumor stages but the functional significance of the RET/PTC-RAS$B R A F$ cascade has not been elucidated yet [42].

The association among Hashimoto's thyroiditis, $B R A F^{V 600 E}$ mutation status, and the clinicopathologic features of papillary carcinoma has been studied. Hashimoto's thyroiditis was negatively associated with $B R A F^{V 600 E}$ mutation, extrathyroidal extension in papillary carcinoma with $B R A F^{V 600 E}$ mutation. The conclusion is that Hashimoto's thyroiditis and lymphocytic infiltration of Hashimoto's thyroiditis are a potentially protective factor in papillary carcinoma against its progression, and it is independent of $B R A F$ mutational status [43-45]. In a study, no BRAF or RAS mutations or RET-PTC rearrangements were identified in the dominant nodule in Hashimoto's thyroiditis [46]. On the other hand in Korean patients with, papillary carcinoma the $B R A F^{V 600 E}$ mutation is associated with a lower frequency of background Hashimoto's thyroiditis and a high frequency of lymph node metastasis. Subgroups categorized by $B R A F^{V 600 E}$ mutation and Hashimoto's thyroiditis status were significantly associated with the risk of higher stage and, thus, Hashimoto's thyroiditis and $B R A F^{V 600 E}$ mutation may help to predict clinical outcome of papillary carcinoma [47]. On the other hand, $B R A F$ mutation is not present in the atypical follicular epithelium of Hashimoto thyroiditis [48]. These data suggest that $B R A F$ is a less frequent mechanism of tumorogenesis in a background of Hashimoto's thyroiditis.

Ultrasono can be used to assess stages of the disease and to identify nodules, occur in around $10 \%$ of patients. The cancerous tissue with a papillary structure was hypoechogenic and the amount of fibrous stroma determined whether the nodule echogenicity was heterogeneous or homogeneous. Heterogeneous echogenicity was associated with a fibrous with a higher stroma proportion. Ultrasonographic features of thyroid cancer are similar in patients with and without Hashimoto's thyroiditis and the sonographic appearance of the cancerous nodule is similar, except that cancerous nodule margins are irregular or poorly defined when the gland is heterogeneous $[49,50]$. 
The relationship between thyroid lymphoma and Hashimoto's thyroiditis appears to be well established [2] but the association of Hashimoto's thyroiditis and thyroid cancer remains a matter of research and controversy, who was the first thyroiditis or cancer? The relationship between this concurrent disease that was first proposed in 1955 and that has been explored the epidemiology and etiology of both processes, but the relationship between both conditions is therefore unclear. It should be elucidated whether chronic thyroiditis predisposes to development of papillary thyroid carcinoma, or is a concurrent incidental finding, or thyroiditis is part of a host response to the tumor [51-54]. Concomitant occurrence of both conditions represents a challenge for clinicians, who see this association with some frequency without clarification and pending of the help of information from basic research. For the time being, and in the absence of stronger evidence, patients with Hashimoto's thyroiditis, and mainly those with the nodular variant, must be regularly monitored, and the possibility of development of papillary carcinoma, which is uncommon, must be bear in mind that either at diagnosis or during follow-up the patient can present a thyroid tumor.

\section{References}

1. Krátký J, Jiskra J (2015) [Autoimmune thyroiditis and thyroid cancer]. Vnitr Lek 61: 878-881.

2. Troch M, Woehrer S, Streubel B, Weissel M, Hoffmann M, et al. (2008) Chronic autoimmune thyroiditis (Hashimoto's thyroiditis) in patients with MALT Iymphoma. Ann Oncol 19: 1336-1339.

3. Kebebew E, Treseler PA, Ituarte PH, Clark OH (2001) Coexisting chronic lymphocytic thyroiditis and papillary thyroid cancer revisited. World J Surg 25: 632-637.

4. Gómez Saez JM, Gómez Arnaiz N, Sahun de la Vega M, Soler Ramón J (1997) [Prevalence and significance of lymphocyte infiltration in papillary carcinoma of the thyroid gland]. An Med Interna 14: 403-405.

5. Harach HR, Williams ED (1995) Thyroid cancer and thyroiditis in the goitrous region of Salta, Argentina, before and after iodine prophylaxis. Clin Endocrinol (Oxf) 43: 701-706.

6. Oh CM, Park S, Lee JY, Won Y, Shin A, et al. 2014 Increased Prevalence of Chronic Lymphocytic Thyroiditis in Korean Patients with Papillary Thyroid Cancer. PLoS One 9: 99054.

7. Enewold L, Zhu K, Ron E, Marrogi AJ, Stojadinovic A, et al. (2009) Rising thyroid cancer incidence in the United States by demographic and tumor characteristics, 1980-2005. Cancer Epidemiol Biomarkers Prev 18: 784-791.

8. Chen AY, Jemal A, Ward EM (2009) Increasing incidence of differentiated thyroid cancer in the United States, 1988-2005. Cancer 115: 3801-3807.

9. Koibuchi H, Omoto K, Fukushima N, Toyotsuji T, Taniguchi N, et al. (2014) Coexistence of papillary thyroid cancer and Hashimoto thyroiditis in children report of 3 cases. J Ultrasound Med 33: 1299-1303.

10. Kebebew E, Treseler PA, Ituarte PH, Clark OH (2001) Coexisting chronic lymphocytic thyroiditis and papillary thyroid cancer revisited. World J Surg 25: $632-637$

11. Kim KW, Park YJ, Kim EH, Park SY, Park do J, et al. (2011) Elevated risk of papillary thyroid cancer in Korean patients with Hashimoto's thyroiditis. Head Neck 33: 691-695.

12. Ahn D, Heo SJ, Park JH, Kim JH, Sohn JH, et al. (2011) Clinical relationship between Hashimoto's thyroiditis and papillary thyroid cancer. Acta Oncol 50: 1228-1234.

13. Ye ZQ, Gu DN, Hu HY 2013 Hashimoto's thyroiditis, microcalcification and raised thyrotropin levels within normal range are associated with thyroid cancer. World J Surg Oncol 11:56.
14. Liu CL, Cheng SP, Lin HW, Lai YL (2014) Risk of thyroid cancer in patients with thyroiditis: a population-based cohort study. Ann Surg Oncol 21: 843849 .

15. Larson SD, Jackson LN, Riall TS, Uchida T, Thomas RP, et al. (2007) Increased incidence of well-differentiated thyroid cancer associated with Hashimoto thyroiditis and the role of the PI3k/Akt pathway. J Am Coll Surg 204: 764-773.

16. Jankovic B, Le KT, Hershman JM (2013) Clinical Review: Hashimoto's thyroiditis and papillary thyroid carcinoma: is there a correlation? J Clin Endocrinol Metab 98: 474-482.

17. Kim EY, Kim WG, Kim WB, Kim TY, Kim JM, et al. (2009) Coexistence of chronic lymphocytic thyroiditis is associated with lower recurrence rates in patients with papillary thyroid carcinoma. Clin Endocrinol (Oxf) 71: 581-586.

18. Ludvíková M, Ryska A, Korabecná M, Rydlová M, Michal M (2001) Oncocytic papillary carcinoma with lymphoid stroma (Warthin-like tumour) of the thyroid: a distinct entity with favourable prognosis. Histopathology 39: 17-24.

19. Anil C, Goksel S, Gursoy A (2010) Hashimoto's thyroiditis is not associated with increased risk of thyroid cancer in patients with thyroid nodules: a single-center prospective study. Thyroid 20: 601-606.

20. Grani G, Calvanese A, Carbotta G, D'Alessandri M, Nesca A, et al. (2015) Thyroid autoimmunity and risk of malignancy in thyroid nodules submitted to fine-needle aspiration cytology. Head Neck 37: 260-264.

21. Fiore E, Rago T, Latrofa F, Provenzale MA, Piaggi P, et al. (2011) Hashimoto's thyroiditis is associated with papillary thyroid carcinoma: role of TSH and of treatment with L-thyroxine. Endocr Relat Cancer 18: 429-437.

22. Kim ES, Lim DJ, Baek KH, Lee JM, Kim MK, et al. (2010) Thyroglobulin antibody is associated with increased cancer risk in thyroid nodules. Thyroid 20: 885-891.

23. McLeod DS, Cooper DS, Ladenson PW, Ain KB, Brierley JD, et al. (2014) Prognosis of differentiated thyroid cancer in relation to serum thyrotropin and thyroglobulin antibody status at time of diagnosis. Thyroid 24: 35-42.

24. Wong SL, Grodski S, Yeung MJ, Serpell JW (2015) Anti-thyroid antibodies as a predictor of thyroid cancer. ANZ J Surg 85: 849-853.

25. Haymart MR, Repplinger DJ, Levenson G, Elson DF, Sippel RS, et al. (2008) Higher serum thyroid stimulating hormone level in thyroid nodule patients is associated with greater risks of differentiated thyroid cancer and advanced tumor stage. J Clin Endocrinol Metab 93: 809-814.

26. Zafón C, Obiols G, Baena JA et al (2012) Preoperative thyrotropin serum concentrations gradually increase from benign thyroid nodules to papillary thyroid microcarcinomas then to papillary thyroid cancers of larger size. $\mathrm{J}$ Thyroid Res: 530721.

27. Paparodis R, Imam S, Todorova-Koteva K, Staii A, Jaume JC (2014) Hashimoto's thyroiditis pathology and risk for thyroid cancer. Thyroid 24: $1107-1114$

28. Jara SM, Carson KA, Pai SI, Agrawal N, Richmon JD, et al. (2013) The relationship between chronic lymphocytic thyroiditis and central neck lymph node metastasis in North American patients with papillary thyroid carcinoma. Surgery 154:1272-1280.

29. Loh KC, Greenspan FS, Dong F, Miller TR, Yeo PP (1999) Influence of lymphocytic thyroiditis on the prognostic outcome of patients with papillary thyroid carcinoma. J Clin Endocrinol Metab 84: 458-463.

30. Kim EY, Kim WG, Kim WB, Kim TY, Kim JM, et al. (2009) Coexistence of chronic lymphocytic thyroiditis is associated with lower recurrence rates in patients with papillary thyroid carcinoma. Clin Endocrinol (Oxf) 71: 581-586.

31. Cunha LL, Ferreira RC, Marcello MA, Vassallo J, Ward LS (2011) Clinical and pathological implications of concurrent autoimmune thyroid disorders and papillary thyroid cancer. J Thyroid Res 2011: 387062.

32. Huang BY, Hseuh C, Chao TC, Lin KJ, Lin JD (2011) Well-differentiated thyroid carcinoma with concomitant Hashimoto's thyroiditis present with less aggressive clinical stage and low recurrence. Endocr Pathol 22: 144-149. 
33. Dvorkin S, Robenshtok E, Hirsch D, Strenov Y, Shimon I, et al. (2013) Differentiated thyroid cancer is associated with less aggressive disease and better outcome in patients with coexisting Hashimotos thyroiditis. J Clin Endocrinol Metab 98: 2409-2414.

34. Lun Y, Wu X, Xia Q, Han Y, Zhang X, et al. (2013) Hashimoto's thyroiditis as a risk factor of papillary thyroid cancer may improve cancer prognosis. Otolaryngol Head Neck Surg 148: 396-402.

35. Kim SS, Lee BJ, Lee JC, Kim SJ, Jeon YK, et al. (2011) Coexistence of Hashimoto's thyroiditis with papillary thyroid carcinoma: the influence of lymph node metastasis. Head Neck 33: 1272-1277.

36. Lai V, Yen TW, Rose BT, Fareau GG, Misustin SM, et al. (2015) The Effect of Thyroiditis on the Yield of Central Compartment Lymph Nodes in Patients with Papillary Thyroid Cancer. Ann Surg Oncol 22: 4181-4186.

37. Paparodis R, Imam S, Todorova-Koteva K, Staii A, Jaume JC (2014) Hashimoto's thyroiditis pathology and risk for thyroid cancer. Thyroid 24: 1107-1114.

38. Iliadou PK, Effraimidis G, Konstantinos, Grigorios, Mitsakis, et al. (2015) Chronic lymphocytic thyroiditis is associated with invasive characteristics of differentiated thyroid carcinoma in children and adolescents. Eur J Endocrinol 173: $827-833$

39. Gogali F, Paterakis G, Rassidakis GZ et al 2013 CD3(-)CD16(-)CD56(bright) immunoregulatory NK cells are increased in the tumor microenvironment and inversely correlate with advanced stages in patients with papillary thyroid cancer. Thyroid 23:156-158.

40. Zivancevic-Simonovic S, Mihaljevic O, Majstorovic I, Popovic S, Markovic S, et al. (2015) Cytokine production in patients with papillary thyroid cancer and associated autoimmune Hashimoto thyroiditis. Cancer Immunol Immunother 64: 1011-1019.

41. Park SH, Park CS, Kim YI, Nam-Goong IS, Kim YS, et al. (2015) Osteopontin levels in patients with papillary thyroid cancer according to the presence of Hashimoto's thyroiditis. Asian Pac J Cancer Prev 16: 2447-2451.

42. Kang DY, Kim KH, Kim JM, Kim SH, Kim JY, et al. (2007) High prevalence of RET, RAS, and ERK expression in Hashimoto's thyroiditis and in papillary thyroid carcinoma in the Korean population. Thyroid 17: 1031-1038.

43. Zeng RC, Jin LP Chen ED, Dong SY, Cai YF, et al. (2015) Potential relationship between Hashimoto's thyroiditis and BRAFV600E mutation status in papillary thyroid cancer. Head Neck.
44. Marotta V, Guerra A, Zatelli MC, Uberti ED, Di Stasi V, et al. (2013) BRAF mutation positive papillary thyroid carcinoma is less advanced when Hashimoto's thyroiditis lymphocytic infiltration is present. Clin Endocrinol (Oxf) 79: 733-738.

45. Kim SK, Woo JW, Lee JH, Park I, Choe JH, et al. (2016) Chronic lymphocytic thyroiditis and BRAF V600E in papillary thyroid carcinoma. Endocr Relat Cancer 23: 27-34.

46. Sadow PM, Heinrich MC, Corless CL, Fletcher JA, Nosé V (2010) Absence of BRAF, NRAS, KRAS, HRAS mutations, and RET/PTC gene rearrangements distinguishes dominant nodules in Hashimoto thyroiditis from papillary thyroid carcinomas. Endocr Pathol 21: 73-79.

47. Kim SJ, Myong JP, Jee HG, Chai YJ, Choi JY, et al. (2016) Combined effect of Hashimoto's thyroiditis and BRAF(V600E) mutation status on aggressiveness in papillary thyroid cancer. Head Neck 38: 95-101.

48. Sargent R, LiVolsi V, Murphy J, Mantha G, Hunt JL (2006) BRAF mutation is unusual in chronic lymphocytic thyroiditis-associated papillary thyroid carcinomas and absent in non-neoplastic nuclear atypia of thyroiditis. Endocr Pathol 17: 235-241.

49. Durfee SM, Benson CB, Arthaud DM, Alexander EK, Frates MC (2015) Sonographic appearance of thyroid cancer in patients with Hashimoto thyroiditis. J Ultrasound Med 34: 697-704.

50. Wang Y, Li L, Wang YX, Feng XL, Zhao F, et al. (2012) Ultrasound findings of papillary thyroid microcarcinoma: a review of 113 consecutive cases with histopathologic correlation. Ultrasound Med Biol 38: 1681-1688.

51. Noureldine SI, Tufano RP (2015) Association of Hashimoto's thyroiditis and thyroid cancer. Curr Opin Oncol 27: 21-25.

52. Azizi G, Keller JM, Lewis M, Piper K, Puett D, et al. (2014) Association of Hashimoto's thyroiditis with thyroid cancer. Endocr Relat Cancer 21: 845-852.

53. Gómez Sáez JM1 (2014) Chronic autoimmune thyroiditis and thyroid cancer Endocrinol Nutr 61: 299-301.

54. Zhang Y, Ma XP, Deng FS, Liu ZR, Wei HQ, et al. (2014) The effect of chronic lymphocytic thyroiditis on patients with thyroid cancer. World J Surg Oncol 12: 277. 